\title{
Medical Expenses Analysis of Middle-Aged and Elderly Patients with Diabetes Mellitus in China
}

\author{
Li Liu, Xue Yu, Jing Deng* \\ Center for Social Risk Governance in Health, Chongqing, China \\ Email address: \\ 1903141920@qq.com (Li Liu),904627564@qq.com (Xue Yu), cqmudj@126.com (Jing Deng) \\ ${ }^{*}$ Corresponding author
}

School of Public Health and Management, Chongqing Medical University, Research Center for Medicine and Social Development, Innovation

\section{To cite this article:}

Li Liu, Xue Yu, Jing Deng. Medical Expenses Analysis of Middle-Aged and Elderly Patients with Diabetes Mellitus in China. International Journal of Health Economics and Policy. Vol. 6, No. 1, 2021, pp. 14-22. doi: 10.11648/j.hep.20210601.12

Received: January 28, 2021; Accepted: February 6, 2021; Published: February 20, 2021

\begin{abstract}
Objective Diabetes is one of the most serious and most critical health problems facing the world in the 21 st century. The number of patients is increasing year by year, and it has a huge impact and burden on individuals and families, society and the country. This study estimates the medical expenses of diabetes in China and provides a basis for implementing diabetes prevention and treatment strategies. Methods Using the 2015 China Health and Retirement Longitudinal Study (CHARLS), the propensity score matching (PSM) was used to solve the sample selection bias to study the impact of diabetes on residents' outpatient, hospitalization and total direct health expenditure. At the same time, attribution analysis is used to measure the part of the health expenditure of Chinese diabetic patients attributable to diabetes. Results Diabetes significantly increased the health expenditure of residents. The outpatient, hospitalization and total direct health expenditures of Chinese diabetic patients were significantly higher than those of non-diabetic patients. Among them, the difference in hospitalization expenses was the largest; $62.69 \%$ of the total expenditures of Chinese diabetic patients were attributed to diabetes. Conclusion Diabetes medical expenses are high, and diabetes-related treatment costs are high. We should expand the support and awareness of diabetes-related medical insurance compensation policies, strengthen early diabetes intervention and health education, and improve drug compensation policies to effectively reduce diabetes medical expenses.
\end{abstract}

Keywords: Diabetes, Medical Expenses, PSM, Attribution Analysis

\section{Introduction}

According to the latest data released by the International Diabetes Federation (IDF) [1], the number of diabetes patients in China ranked first in the world in 2019, reaching 116.4 million, and it is expected to remain the highest in 2045, reaching 147 million. With population growth and aging intensification, the number of diabetes patients in China will further rise. Diabetes has a long course, not obvious at the initial stage, and many complications, which brings a huge economic burden of disease to individuals and society. It can be seen from the Diabetes Atlas published by IDF that from 2013 to 2019, China's diabetes medical expenditure increased from 38 billion U.S. dollars (about 231.4 billion yuan) [2] to 109 billion U.S. dollars (about 752.1 billion yuan). The growth rate was $19 \%$, much higher than the $11 \%$ growth rate of total health expenditure during the same period. China's diabetes medical expenses are high and the growth trend is fast. Calculating the various components of China's diabetes medical expenses and analyzing the distribution of diabetes medical expenses can clearly understand the consumption of diabetes health resources, so as to provide a reference for exploring ways to effectively reduce diabetes medical and health expenditures.

Researches on diabetes medical expenses in China have shown that diabetes has brought a heavy disease economic burden to patients and society. Xu Nan (2016) and others estimated that the total annual medical expenses of China's diabetes treatment population in 2013 was about $85 \sim 100$ billion yuan, and its average annual real growth rate was $15.14 \%$, which exceeded the GDP growth rate in the same period [3]; A study by Mingxing Yu (2019) and others showed that the total economic burden of diabetes patients in Sichuan Province in 2014 reached 7.06 billion yuan, of 
which the direct economic burden was 6.01 billion yuan [4]; In 2015, Leng Yao (2018) and others estimated that the per capita economic burden of disease for middle-aged and elderly diabetic patients in China was 9594.1 yuan/year, and the population's disease economic burden accounted for $0.38 \%$ of GDP in the same year, which was 259.86 billion yuan [5]; In 2016, the total disease economic burden of diabetic patients with one and two or more complications was 9,035 yuan and 14,333 yuan, respectively. The total disease economic burden of diabetic patients in Jiangsu Province reached 27.1 billion yuan, accounting for the region's GDP that year of $0.35 \%$ [6]. Through the above research, it can be found that the current estimates of diabetes costs in China are all the health expenditures of diabetic patients, and it is not clearly stated how many of them are caused by diabetes, that is, the health expenditures attributed to diabetes. Therefore, there is a certain degree of bias in the measurement results. Diabetes will increase the risk of other complications or chronic diseases, especially middle-aged and elderly patients are often accompanied by other chronic complications. Diabetes has also increased the treatment costs of general diseases that are not directly related to diabetes, and has brought a heavy excess economic burden of diabetes, and how much of this is attributed to diabetes, currently few studies in China have clearly pointed out.

The research on diabetes-related medical expenses in foreign countries has been carried out earlier and has formed a relatively mature method and system for calculation. Among them, with the United States as the representative, the American Diabetes Association has used the attributable risk method to measure the economic burden of diabetes in the United States every few years since 1978. In 2012, the average annual medical expenses for people with diagnosed diabetes in the United States was approximately US\$13,700, of which approximately US\$7,900 was attributed to diabetes. On average, the medical expenditures of people diagnosed with diabetes are about 2.3 times higher than those without diabetes. Medical care expenditures for patients with diagnosed diabetes account for more than one-fifth of the country's total health expenditures, and more than half of the expenditures are directly attributable to diabetes. By 2017, the health expenditure of patients with diagnosed diabetes accounted for a quarter of the total health expenditure of the country, and more than half of the expenditure was still directly attributable to diabetes [7-8]. The United States can dynamically and clearly control the impact of diabetes on individuals and society through regular quantitative analysis of the national diabetes medical resource consumption, evaluate the economic benefits of health investment and disease prevention measures, and provide a basis for scientifically and rationally formulating corresponding health policies.

Therefore, based on the above questions, this study uses the 2015 China Health and Retirement Longitudinal Study (CHARLS). First, single factor analysis is used to test the difference in medical and health expenditure between patients and non-patients; second, it uses propensity score matching (PSM) Construct a counterfactual framework to eliminate sample selection bias, so as to accurately measure the difference in medical and health expenditures between patients and non-patients; finally, use attribution scores to calculate the cost attributable to diabetes in China and evaluate the additional direct disease economy of diabetes Burden, provide a basis for the rational allocation of health resources and the formulation of diabetes policies.

\section{Data and Methods}

\subsection{Data and Variables}

\subsubsection{Data Sources}

The main data of this study comes from the 2015 CHARLS database. The DA007 question in the CHARLS questionnaire database "has any doctor ever told you that you have the following chronic diseases?" and the DA014 question "Are the following methods currently used to treat and control diabetes?" to screen diabetic patients. The specific screening process is shown in Figure 1.

\subsubsection{Variable Selection and Descriptive Statistics}

Explained variables: This study mainly takes outpatient expenses, hospitalization expenses and total direct health expenses as outcome variables. The total direct health expenses are expenses including self-treatment expenses, and the above expenses are all direct medical expenses, excluding direct non-medical expenses such as transportation, boarding and lodging caused by medical treatment, and indirect labor income lost due to illness. cost. Because in the later attribution analysis, the medical expense data in the cited national database also refers to direct health expenses, and includes two parts: medical insurance expenses and personal out-of-pocket expenses. In order to eliminate heteroscedasticity, this study uses logarithmic treatment for health expenditure when doing regression analysis. Since some expenses have a value of 0 , health expenditures are set in the form of $\ln$ (medical expenses+1).

Core explanatory variable: whether it is a diabetic patient (diabetic patient $=1$, non-diabetic patient $=0$ )

Control variables: In order to control other factors that may affect health expenditures, referring to the previous literature [4, 9], the following control variables are introduced: age, gender, education level, urban and rural categories, health insurance type, smoking, drinking, obesity, Combined with the number of other chronic diseases, and self-evaluated health status. The specific definition of variables and descriptive results are shown in the following table: 


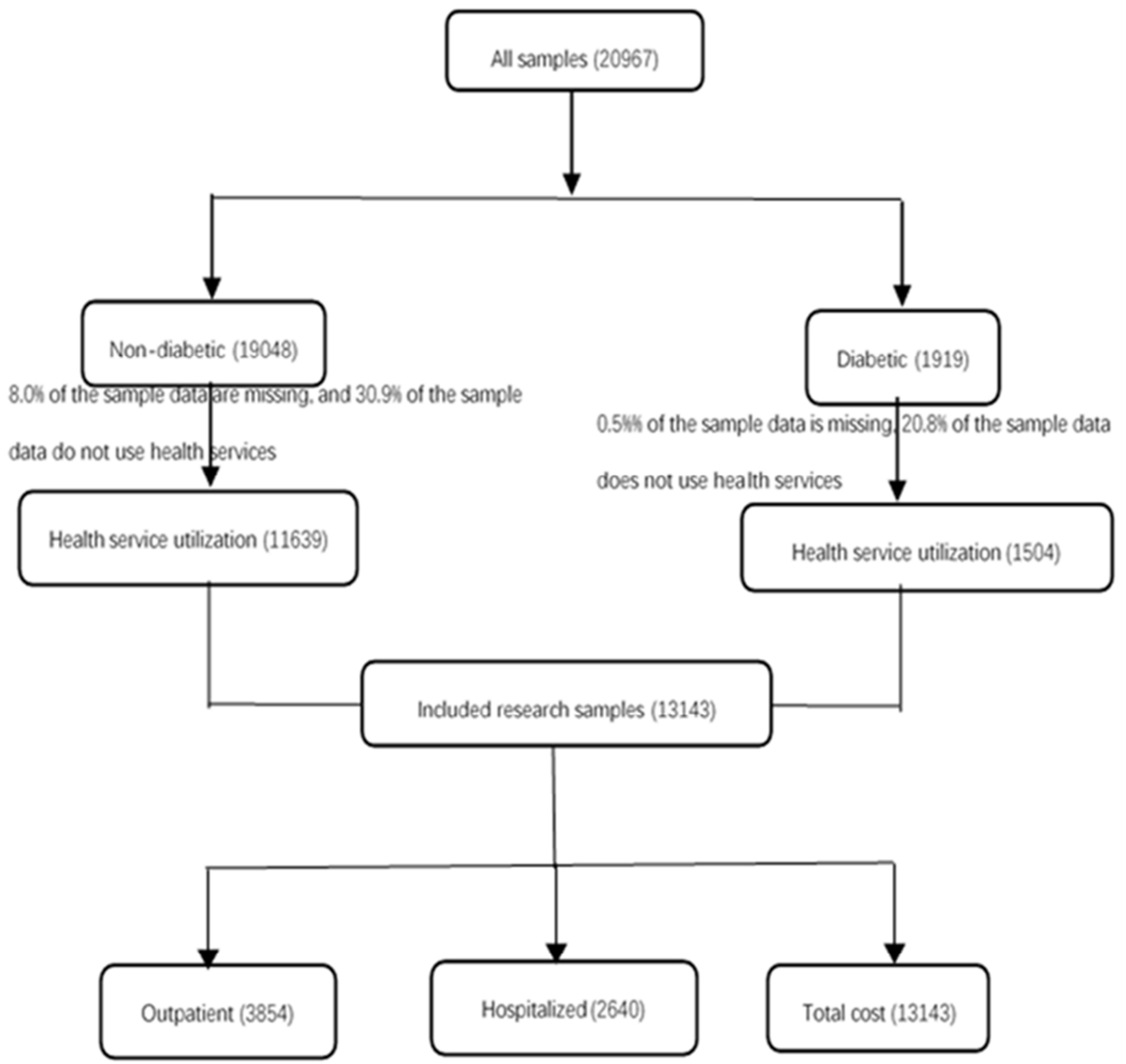

Figure 1. Data filtering process diagram.

Table 1. Variable statistical description.

\begin{tabular}{|c|c|c|c|}
\hline Variable name & Variable description & Mean & Standard deviation \\
\hline \multicolumn{4}{|l|}{ Explained variable } \\
\hline Annual outpatient expenditure per capita & Logarithmic form & 6.81 & 1.81 \\
\hline Outpatient pay ratio & Continuous variable & 0.82 & 0.32 \\
\hline Outpatient pay ratio & Continuous variable & 0.58 & 0.41 \\
\hline Annual inpatient expenditure per capita & Logarithmic form & 6.8 & 1.42 \\
\hline Inpatient pay ratio & Continuous variable & 0.61 & 0.33 \\
\hline Proportion of hospitalized drugs & Continuous variable & 0.56 & 0.60 \\
\hline $\begin{array}{l}\text { Total direct health expenditure per capita } \\
\text { Explanatory variables }\end{array}$ & \multicolumn{2}{|c|}{ Explanatory variables } & 1.84 \\
\hline age & Continuous variable & 60.58 & 9.84 \\
\hline sex & $1=$ Male, $2=$ Female & 1.54 & 0.50 \\
\hline Number of complications & Continuous variable & 2.1 & 1.72 \\
\hline Urban and Rural Categories & $0=$ urban, $1=$ rural & 0.68 & 0.47 \\
\hline & $\begin{array}{l}\text { 1=Elementary education and below (illiterate, not graduated from } \\
\text { elementary school and graduated); }\end{array}$ & & \\
\hline Education level & $\begin{array}{l}\text { 2=Secondary education (junior high school, technical secondary school, } \\
\text { high school graduation); } \\
3=\text { Higher education (college and above) }\end{array}$ & 1.32 & 0.51 \\
\hline Medical insurance type & $\begin{array}{l}\text { 1=Urban employee medical insurance, } \\
2=\text { Urban Resident Medical Insurance, } \\
3=\text { New Rural Cooperative Medical Insurance, } \\
4=\text { No medical insurance }\end{array}$ & 2.79 & 0.89 \\
\hline Smoking & $0=$ No, $1=$ Yes & 0.26 & 0.44 \\
\hline drink & $0=$ No, $1=$ Yes & 0.47 & 0.50 \\
\hline obesity & $\begin{array}{l}1=\text { Lighter weight, } 2=\text { Normal weight, } \\
3=\text { overweight, } 4=\text { obesity }\end{array}$ & 2.52 & 0.78 \\
\hline Self-rated health & $0=$ Poor, $1=$ General, $2=$ Good & 0.93 & 0.65 \\
\hline
\end{tabular}




\subsection{Research Methods}

\subsubsection{PSM Method}

Related research on the medical expenses of diabetic patients basically shows that the medical expenses of diabetic patients are higher than that of non-patients. But before the comparison, the difference in the initial conditions of the two groups of people, such as age, education level, etc., will directly affect the accuracy of the comparison results. At the same time, in some cases, some people with diabetes may choose not to use health services even if they have diabetes. One situation may be undiagnosed. Diabetes itself is a chronic disease. The symptoms are not obvious at the beginning of the onset, and patients will not use health services without knowing that they are sick. Another situation is that patients may not use health services due to economic conditions, inconvenient transportation, etc., so that they will not incur health expenses; In addition, even if patients use health services, it is possible that problems such as poor compliance and irregular treatment during the treatment process will affect health expenditures and bias the estimation of health expenditures. Therefore, it cannot be directly assumed that the health expenditure of diabetic patients is higher than that of non-diabetic patients, or that part of the health expenditure of diabetic patients is caused by diabetes. There are many factors that affect whether residents have diabetes or not, but also affect the applicability of their medical and health expenditures. Therefore, in order to investigate the impact of diabetes on residents' medical and health expenditures, this study introduced the PSM model to solve [10]. This model selects individuals from the control group (non-diabetic group) based on the propensity score and matches the test group (diabetic group) individuals, eliminating the heterogeneity of the observable basic characteristics of the two groups of individuals. The final difference in medical expenses between the two groups of people is mainly attributed to diabetes. The specific implementation process is as follows:

First, use the logit model to estimate the probability of having diabetes, that is, the propensity score (PS):

$$
p_{i}(x)=\operatorname{pr}\left(\text { diabetes }=1 \mid X_{i}\right)=\mathrm{F}\left[h\left(x_{i}\right)\right]
$$

Among them, diabetes is the dependent variable, which represents whether or not there is diabetes (diabetes $=1$, yes; diabetes $=0$, no) $X_{i}$ represents a series of characteristic variables that individual $i$ has diabetes, and the variables are included as described above.

Second, the sample matching effect test. After checking the matching, whether there are systematic differences in the sample characteristics between the experimental group and the control group.

Finally, calculate the average treatment effect. By comparing the difference in the utilization and cost of health services between the experimental group and the control group, the impact of diabetes on the utilization and cost of residents' medical and health services is obtained, which is the estimated amount of ATT. To ensure the robustness of the estimation results, this study selects nearest neighbor matching ( 1 to 1 without replacement), radius matching (caliper value 0.01 ) and kernel matching for sample matching If the matching estimation results of the three methods are similar, the estimated result is stable and reliable. The expression of ATT estimator is:

$$
A T T=\frac{1}{N_{1}} \Sigma_{\mathrm{i}: D_{i}=1}\left(y_{i}-y_{0 i}\right)
$$

In the formula, $N_{1}=\Sigma_{1} D_{i}$ refers to the number of samples in the experimental group, $\Sigma_{\mathrm{i}: D_{i}}$ refers to only adding up the samples in the experimental group, $\mathrm{y}_{\mathrm{i}}$ is the medical service utilization and cost status of the samples in the experimental group, and $\mathrm{y}_{0 \mathrm{i}}$ is the medical service utilization and expense status of the control group sample after matching.

\subsubsection{Attribution Analysis}

This study uses the formula recommended by IDF [11] to measure the total direct health expenditure of Chinese diabetic patients and the health expenditure caused by diabetes. To quantify the economic burden of disease brought by diabetes to society, the specific formula is calculated as follows:

$E_{1}$ refers to the direct health expenditure attributable to diabetes in the total national health expenditure, $\frac{P\left(R_{o, i, s, t}-1\right)-1}{P\left(R_{o, i, s,}-1\right)+1}$ is the attribution (cause) score, which represents the proportion of the total health expenditure attributable to diabetes. Among them, $\mathrm{P}$ represents the prevalence of diagnosed diabetes, o represents outpatient expenditure (outpatient), I represents hospitalization expenditure (inpatient), $\mathrm{s}$ represents self-treatment expenditure (self-treatment), d represents outpatient or hospitalization drug expenditure, $\mathrm{t}$ Represents the total expenditure (total), $\mathrm{R}$ represents the ratio of the annual per capita health expenditures of diabetic patients and non-patients, and $U$ represents the total expenditure of various parts of China:

$$
E_{1}=\frac{P\left(R_{o, i, d, t}-1\right)-1}{P\left(R_{o, i, d, t}-1\right)+1} U_{o, i, d, t}
$$

$E_{2}$ refers to the country's direct health expenses for diabetic patients (including direct health expenses attributable to diabetes and direct health expenses not related to diabetes treatment).

$$
E_{2}=\frac{P\left(R_{o, i, d, t}-1\right)}{P\left(R_{o, i, d, t}-1\right)+1} U_{o, i, d, t}
$$

This research gives the following explanations for the indicators involved in the calculation of the above formula. The prevalence of diabetes $\mathrm{P}$ is based on the CHARLS data sample (9.76\%); there is no total health expenditure data for each part of the cost in the relevant statistics in China, the calculation of the total annual cost of outpatient and hospitalization is based on 2016 Calculated by "China Health and Family Planning Statistical Yearbook". Among them, the 
total annual outpatient cost=average outpatient medical expenses $\times$ total number of patients; total annual hospitalization cost=average medical expenses per inpatient $x$ the number of people discharged; the total health cost directly uses the total health cost in the statistical yearbook; the total annual outpatient drug cost=Average outpatient drug cost per time $\times$ total number of patients; total annual hospitalized drug cost=per capita hospitalized drug cost $\times$ number of discharged patients.

\section{Result}

\subsection{The Impact of Diabetes on Medical Expenses}

The total outpatient expenses, total hospitalization expenses, and total direct health expenses of diabetic patients are higher than those of non-diabetic patients, and the proportion of outpatient expenses and the proportion of medicines are lower than those of non-diabetics, but it cannot be directly considered that diabetes has caused medical and health expenditures influences. At the same time, the difference in the ratio of hospitalization and the proportion of medicines between patients and non-patients is not significant, and it cannot be directly assumed that there is no difference between the two groups of people in the above two aspects. To make an accurate assessment, it is necessary to eliminate the differences in individual characteristics between the two groups of sample populations to avoid possible estimation biases. Therefore, it also confirms the effectiveness of using the PSM method to accurately evaluate the impact of diabetes on medical and health expenditures.

Table 2. Analysis of the impact of diabetes on medical expenses.

\begin{tabular}{|c|c|c|c|c|c|c|c|c|}
\hline \multirow{2}{*}{ Eigenvalues } & \multicolumn{2}{|c|}{$\begin{array}{l}\text { Total annual outpatient } \\
\text { expenses }\end{array}$} & \multicolumn{2}{|c|}{ Outpatient pay ratio ${ }^{* * *}$} & \multicolumn{2}{|c|}{ Proportion of outpatient drugs } & \multicolumn{2}{|c|}{$\begin{array}{l}\text { Total annual hospitalization } \\
\text { expenses }\end{array}$} \\
\hline & patient & Non-patient & patient & Non-patient & patient & Non-patient & patient & Non-patient \\
\hline Mean & 7.61 & 6.68 & 0.79 & 0.83 & 0.60 & 0.58 & 7.73 & 6.59 \\
\hline Standard deviation & 1.81 & 1.78 & 0.33 & 0.31 & 0.41 & 0.41 & 1.21 & 1.38 \\
\hline Mini & 0.00 & 0.00 & 0.00 & 0.00 & 0.00 & 0.00 & 0.00 & 0.00 \\
\hline $\operatorname{Max}$ & 12.28 & 11.80 & 1.00 & 1.00 & 1.00 & 1.00 & 10.67 & 9.74 \\
\hline Sample & 512 & 3342 & 512 & 3342 & 463 & 3069 & 497 & 2143 \\
\hline
\end{tabular}

Table 2. Continued.

\begin{tabular}{llllll}
\hline \multirow{2}{*}{ Eigenvalues } & \multicolumn{2}{l}{ Inpatient pay ratio } & \multicolumn{2}{l}{ Proportion of hospitalized drugs } & \multicolumn{2}{c}{ Total annual direct health expenditure *** } \\
\cline { 2 - 6 } & patient & Non-patient & patient & Non-patient & patient \\
\hline Mean & 0.59 & 0.61 & 0.50 & 0.52 & 7.57 \\
Standard deviation & 0.33 & 0.33 & 0.36 & 0.39 & 1.81 \\
Mini & 0.00 & 0.00 & 0.00 & 0.00 & 0.00 \\
Max & 1.00 & 1.00 & 1.00 & 1.00 & 1.80 \\
Sample & 497 & 2143 & 279 & 1110 & 11.38 \\
\hline
\end{tabular}

note: $* \mathrm{p}<0.1, * * \mathrm{p}<0.05, * * * \mathrm{p}<0.01$

\subsection{Robust Analysis of the Impact of Diabetes on Medical Expenses}

\subsubsection{Balance Test}

From the above analysis results, it can be seen that the medical and health expenditure of diabetic patients is significantly higher than that of non-patients, but it cannot be judged from this that diabetes promotes the increase in health expenditure of patients, because there may be many other reasons that have played a role in it. Therefore, this study uses a PSM analysis based on a counterfactual framework to reassess the impact of diabetes on health care expenditures, and uses a logit model to estimate propensity scores to match non-diabetic counterfactual individuals for each diabetic patient. The balance test results of the matching variables showed that after PSM, the differences in individual characteristics between the two groups of people were eliminated, and the comparability of the two groups of samples was enhanced to effectively evaluate the impact of diabetes on medical and health expenditures.
Parallel hypothesis and common support hypothesis are the prerequisites for using propensity value matching. The balance test results of each variable show (Table 3 ) that the absolute value of the standard deviation of each control variable after matching is basically less than $15 \%$, which is lower than the standard defined by Rosenbaum and Rubin that the absolute value of the standard deviation is less than $20 \%$ [10]. The p-values of most variables cannot reject the null hypothesis that the control variables are not different between the diabetes group and the non-diabetic group, indicating that after matching, the difference in characteristics of the two groups of sample populations is effectively controlled, and the matching effect is good. Outpatient out-of-pocket ratio and inpatient out-of-pocket ratio control variable balance test results are the same as the results of total outpatient expenses and total hospital expenses, so they are not listed here. Due to the space impact, the nearest neighbor matching is taken as an example to show the balance test results of the treatment group and the 
experimental group. The test results of radius matching and nuclear matching are similar to Table 3.

Table 3. Test results of matching variable balance.

\begin{tabular}{|c|c|c|c|c|c|c|c|c|c|}
\hline \multirow[b]{2}{*}{ variable } & \multicolumn{3}{|c|}{$\begin{array}{l}\text { Total annual outpatient expenses } \\
(\mathrm{n}=\mathbf{3 8 0 2})\end{array}$} & \multicolumn{3}{|c|}{ Proportion of outpatient drugs $(n=2847)$} & \multicolumn{3}{|c|}{$\begin{array}{l}\text { Total annual hospitalization expenses } \\
(\mathrm{n}=2604)\end{array}$} \\
\hline & $\begin{array}{l}\text { Deviation after } \\
\text { matching }(\%)\end{array}$ & $\begin{array}{l}\text { Reduce deviation } \\
\text { after matching } \\
\text { (\%) }\end{array}$ & $\begin{array}{l}P \\
\text { value }\end{array}$ & $\begin{array}{l}\text { Deviation after } \\
\text { matching }(\%)\end{array}$ & $\begin{array}{l}\text { Reduce deviation } \\
\text { after matching } \\
(\%)\end{array}$ & $\begin{array}{l}P \\
\text { value }\end{array}$ & $\begin{array}{l}\text { Deviation after } \\
\text { matching }(\%)\end{array}$ & $\begin{array}{l}\text { Reduce } \\
\text { deviation after } \\
\text { matching (\%) }\end{array}$ & $\begin{array}{l}P \\
\text { value }\end{array}$ \\
\hline age & 4.1 & 74.9 & 0.515 & -8.3 & 53.9 & 0.214 & -4.5 & 7.4 & 0.473 \\
\hline $\operatorname{sex}$ & -3.6 & -29.4 & 0.561 & -4.0 & -93.6 & 0.542 & -3.3 & -40.2 & 0.609 \\
\hline $\begin{array}{l}\text { Number of } \\
\text { complications }\end{array}$ & -1.6 & 97.0 & 0.803 & -2.9 & 94.8 & 0.676 & -3.2 & 92.3 & 0.626 \\
\hline $\begin{array}{l}\text { Urban and Rural } \\
\text { Categories }\end{array}$ & -4.7 & 75.5 & 0.470 & -3.7 & 81.6 & 0.584 & -2.5 & 87.8 & 0.698 \\
\hline Education level & 1.9 & 86.4 & 0.774 & 10.0 & 25.2 & 0.134 & 3.2 & 85.8 & 0.630 \\
\hline Medical insurance type & -12.0 & 46.9 & 0.065 & 0.7 & 96.7 & 0.918 & -2.5 & 87.7 & 0.700 \\
\hline Smoking & 5.4 & -14.4 & 0.375 & 9.8 & -107.3 & 0.119 & -2.0 & 80.9 & 0.741 \\
\hline drink & -0.4 & 92.9 & 0.949 & 5.8 & -87.8 & 0.380 & 2.4 & 44.3 & 0.700 \\
\hline obesity & -1.8 & 96.0 & 0.783 & -1.7 & 96.6 & 0.804 & -1.3 & 97.2 & 0.845 \\
\hline Self-rated health & 7.3 & 80.1 & 0.218 & -5.6 & 84.9 & 0.377 & -1.6 & 94.8 & 0.796 \\
\hline
\end{tabular}

Table 3. Continued.

\begin{tabular}{|c|c|c|c|c|c|c|}
\hline \multirow[b]{2}{*}{ variable } & \multicolumn{3}{|c|}{ Proportion of hospitalized drugs $(n=1218)$} & \multicolumn{3}{|c|}{ Total annual direct health expenditure $(n=12953)$} \\
\hline & $\begin{array}{l}\text { Deviation after } \\
\text { matching (\%) }\end{array}$ & $\begin{array}{l}\text { Reduce deviation after } \\
\text { matching }(\%)\end{array}$ & P value & $\begin{array}{l}\text { Deviation after } \\
\text { matching }(\%)\end{array}$ & $\begin{array}{l}\text { Reduce deviation } \\
\text { after matching }(\%)\end{array}$ & P value \\
\hline age & 15.7 & -106.1 & 0.056 & 0.1 & 99.7 & 0.980 \\
\hline sex & -9.5 & -215.7 & 0.266 & -2.8 & 59.3 & 0.436 \\
\hline Number of complications & -9.5 & 79.6 & 0.299 & -2.4 & 96.0 & 0.525 \\
\hline Urban and Rural Categories & 6.8 & 71.4 & 0.440 & -3.0 & 85.9 & 0.432 \\
\hline Education level & 10.4 & 63.6 & 0.236 & 6.4 & 57.4 & 0.090 \\
\hline Smoking & -2.8 & 74.8 & 0.738 & 4.4 & 65.2 & 0.204 \\
\hline drink & 3.6 & 11.5 & 0.669 & 5.8 & 12.7 & 0.111 \\
\hline obesity & -1.4 & 97.2 & 0.874 & 1.9 & 95.9 & 0.613 \\
\hline Self-rated health & 1.7 & 93.7 & 0.832 & 4.4 & 89.4 & 0.220 \\
\hline
\end{tabular}

The common support hypothesis requires that the sample feature distributions of the control group and the experimental group overlap to a certain extent to ensure the matching quality. As shown in Table 4, most of the samples in the control group and the experimental group meet the common support hypothesis. Excluding a small number of samples, it has little effect on the average treatment effect estimation result and meets the common support condition. The results of the radius matching and kernel matching tests are similar to Table 4, and most of the samples meet the common support hypothesis.

Table 4. Common support hypothesis analysis.

\begin{tabular}{llllllll}
\hline \multirow{2}{*}{ Group } & \multicolumn{2}{l}{ Total outpatient expenditure } & \multicolumn{2}{l}{ Outpatient pay ratio } & \multicolumn{2}{c}{ Proportion of outpatient drugs } & Total hospitalization expenditure \\
\cline { 2 - 7 } & $\begin{array}{l}\text { Non-common } \\
\text { value }\end{array}$ & $\begin{array}{l}\text { Common } \\
\text { value }\end{array}$ & $\begin{array}{l}\text { Non-common } \\
\text { value }\end{array}$ & $\begin{array}{l}\text { Common } \\
\text { value }\end{array}$ & $\begin{array}{l}\text { Non-common } \\
\text { value }\end{array}$ & $\begin{array}{l}\text { Common } \\
\text { value }\end{array}$ & $\begin{array}{l}\text { Non-common value } \\
\text { Common } \\
\text { value }\end{array}$ \\
\hline Control group & 39 & 3258 & 39 & 3258 & 56 & 2975 & 7 \\
test group & 3 & 502 & 3 & 502 & 4 & 453 & 1 \\
total & 42 & 3760 & 42 & 3760 & 60 & 3428 & 8 \\
\hline
\end{tabular}

Table 4. Continued.

\begin{tabular}{|c|c|c|c|c|c|c|}
\hline \multirow{2}{*}{ Group } & \multicolumn{2}{|l|}{ Inpatient pay ratio } & \multicolumn{2}{|c|}{ Proportion of hospitalized drugs } & \multicolumn{2}{|c|}{ Total direct health costs } \\
\hline & Non-common value & Common value & Non-common value & Common value & Non-common value & Common value \\
\hline Control group & 7 & 2103 & 32 & 1062 & 139 & 11325 \\
\hline test group & 1 & 493 & 2 & 275 & 2 & 1487 \\
\hline total & 8 & 2596 & 34 & 1337 & 141 & 12812 \\
\hline
\end{tabular}

\subsubsection{Analysis of Matching Results}

Different matching methods will produce different common support areas, so that the effects calculated by different matching algorithms will be different. As shown in Table 5, before matching, diabetes significantly affects the health care expenditures of middle-aged and elderly people at the level of $1 \%$. After adopting the three matching methods of proximity matching, radius matching and kernel matching, the significance remains unchanged to $1 . \%$, but the degree of influence has declined. Compared with non-diabetic patients, 
the annual outpatient, hospitalization, and total direct health costs of diabetic patients are $72.3 \%, 109 \%$, and $76.07 \%$ higher, respectively, which are generally similar to the results before matching in Table 2. The research results further show that diabetes has a positive effect on medical costs. The promotion effect is significant and robust.

After matching, the cost of medicines for diabetic patients is $5 \%$ higher than for non-patients (neighborhood matching). Diabetes is a chronic disease that requires long-term medication. Diabetic patients basically rely on medication. In this study, the cost of drugs for diabetic patients accounted for $60 \%$, which shows that drug cost is the most important factor affecting the outpatient cost of diabetic patients. At the same time, the outpatient payout ratio of diabetic patients is lower than that of non-diabetic patients, but it is not obvious. This article speculates that it is mainly due to the following reasons. Although China has introduced a series of policies to increase outpatient compensation for chronic diseases such as diabetes, on the one hand, diabetic patients have insufficient understanding of outpatient medical insurance for special diseases, and on the other hand, because of special disease application conditions and application procedures Complicated, in the case of low compensation, patients may give up the eligibility for special disease reimbursement [12], resulting in patients not directly enjoying the benefits of the policy. For patients with special diseases in outpatient clinics, the scope of reimbursement of drugs is limited to the prescribed basic hypoglycemic drugs, which can only meet the basic drug needs, and the drug costs beyond the scope still need to be paid by themselves. Expensive drug costs and low compensation levels make the outpatient cost of diabetic patients significantly higher than non-patients.

The difference in average annual hospitalization costs between diabetic patients and non-patients is the largest, with patient costs more than twice that of non-patients. Diabetes is generally treated as outpatient, and hospitalization is only taken when the condition is more serious. Diabetes develops to a certain stage, which often leads to a variety of other complications. At this time, both the utilization of health services and the utilization time will increase significantly. Especially in the middle-aged and elderly groups, there are often more chronic complications, which will undoubtedly intensify the increase in hospitalization costs. There is no significant difference in the proportion of out-of-pocket expenses between diabetic patients and non-patients. This article speculates that there are two main points: hospitalization expenses for diabetic patients based on serious and complex conditions have always been maintained at a high level, but the reimbursement amount is limited. For example, the maximum medical insurance reimbursement limit of China Medical Insurance for hospitalization is only 200 yuan, which makes diabetes patients bear higher expenses [13]. At the same time, subjective and objective factors such as the health concept and economic weakness of the middle-aged and elderly will directly affect their use of commercial medical insurance, and cannot play the role of commercial medical insurance in sharing the proportion of out-of-pocket expenses for hospitalization. At the same time, there is no significant difference in the proportion of medicine expenses between diabetic patients and non-patients in the total hospitalization expenses. The proportion of medicines in both groups reached more than $50 \%$, indicating that medicine expenses are the main component of hospitalization expenses and the economic burden. Main source. This suggests that reasonable control of the increase in drug costs will be the key to controlling the burden of hospitalization expenses.

Table 5. Estimated results of the average treatment effect of the impact of diabetes on residents' health expenditure.

\begin{tabular}{|c|c|c|c|c|c|c|}
\hline \multirow{2}{*}{ variable } & \multicolumn{2}{|c|}{ nearest neighbor matching } & \multicolumn{2}{|c|}{ radius matching } & \multicolumn{2}{|c|}{ kernel matching } \\
\hline & ATT & $\mathbf{T}$ & ATT & $\mathbf{T}$ & ATT & $\mathbf{T}$ \\
\hline Total annual outpatient expenses & 0.712 & $5.89^{* * *}$ & 0.716 & $7.86^{* * *}$ & 0.743 & $8.32^{* * *}$ \\
\hline Outpatient pay ratio & -0.015 & -0.66 & -0.016 & -0.96 & -0.018 & -1.09 \\
\hline Proportion of outpatient drugs & 0.058 & $1.97^{* *}$ & 0.028 & 1.30 & 0.023 & 1.07 \\
\hline Total annual hospitalization expenses & 1.106 & $11.44^{* * *}$ & 1.084 & $15.94^{* * *}$ & 1.093 & $16.49^{* * *}$ \\
\hline Inpatient pay ratio & 0.005 & 0.20 & 0.002 & 0.09 & 0.003 & 0.16 \\
\hline Proportion of hospitalized drugs & -0.039 & -1.06 & -0.013 & -0.46 & -0.010 & -0.38 \\
\hline
\end{tabular}

note: $* \mathrm{p}<0.1, * * \mathrm{p}<0.05,{ }^{* * *} \mathrm{p}<0.01$

\subsection{Attribution Analysis of Diabetes Expenditure}

In order to calculate the health expenditure of diabetic patients attributable to diabetes, adjacent matching ( 1 to 1 with replacement) was used to extract matching samples to calculate the ratio of medical and health expenditures of diabetic patients and non-patients. The propensity score matching method separates diabetes factors from other factors that affect patients' medical and health expenditures to examine the net impact of diabetes on patients' medical and health expenditures. The ratio result obtained after the matching has higher credibility. Here, we compare the extracted data in the form of original data of medical and health expenditures. The specific comparison results are shown in Table 6. In this study, the ratio of the total direct health expenditure of diabetic and non-diabetic patients is 2.68, which is smaller than other studies [14-15]. There may be the following reasons: First, the research objects of this study are mainly middle-aged and elderly people. This population is older, has poorer overall physical fitness, and suffers from multiple underlying diseases. Non-diabetic patients may suffer from multiple other diseases, resulting in smaller differences in health costs between patients and non-patients, which is consistent with other research results [15]. The ratio of direct health expenditures for patients with 
diabetes and non-diabetics decreases with age; secondly, according to previous literature studies, the years are relatively long, and as people's health awareness increases, economic income increases, and medical and health services become available Increased sexuality; patients' demand for medical and health services has increased, and non-patients' awareness of health care is also increasing, which is another reason for the smaller difference in health expenditures between patients and non-patients. Finally, this study has adjusted more variables and carried out the value of the caliper used for matching is 0.01 , which means that other factors affecting health costs are balanced between groups as much as possible, with higher matching accuracy and better reflection of the real situation.

It can be seen from Table 6 that the total health expenditure of diabetes patients in China is 920.785 billion yuan, and the direct health expenditure attributable to diabetes accounts for $62.69 \%$ of the total diabetes expenditure, similar to the results of other studies [16]. Diabetes accounts for $66 \%$ of the hospitalization expenditure of diabetic patients. This article speculates that the main reasons are as follows: This study is based on the CHARLS database. The prevalence awareness rate of Chinese diabetes patients is $56.5 \%$, the outpatient treatment rate is $26.68 \%$, and the inpatient treatment rate is only $25.9 \%$, which is a low awareness and utilization rate. The rate has led to the development of diabetes along with other diseases and exacerbated the economic burden of the disease for diabetic patients. Studies have shown that the treatment of related complications and comorbidities is the main contributor to the direct medical expenses of diabetes. Diabetes patients with end-stage renal disease have an average annual medical cost 2.8 times higher than those without the disease [17]. The average annual health care expenditure of people with four or more complications is 20 times that of patients with diabetes but no complications [18]. For the elderly, the frequency of diabetes-related complications is higher, which results in greater treatment costs for diabetes-related complications.

The results of this study also show that diabetes has a huge socio-economic impact. The health expenditure of diabetic patients accounted for $22.47 \%$ of the total health expenditure, and the total inpatient health expenditure of diabetic patients accounted for nearly a quarter of the total inpatient health expenditure that year First, this may squeeze investment in other health-related fields, limit the availability of medical resources for other disease prevention and control and health promotion, and hinder the development of the national economy. As China's aging and urbanization process accelerates, diabetes patients will increase rapidly, and the cost of diabetes treatment will continue to expand.

Table 6. Analysis of health expenditure attributable to diabetes.

\begin{tabular}{lllllll}
\hline & R (patient to & Total cost \\
category & $\begin{array}{l}\text { Total cost } \\
\text { non-patient } \\
\text { ratio) }\end{array}$ & $\begin{array}{l}\mathbf{1 0 0} \text { million } \\
\text { yuan) }\end{array}$ & $\begin{array}{l}\text { Total health expenditure } \\
\mathbf{1 0 0} \text { million } \\
\text { yuan) }\end{array}$ & $\begin{array}{l}\text { Attributable to people with diabetes } \\
\text { (100 million yuan) }\end{array}$ & $\begin{array}{l}\text { Diabetes patients } \\
\text { Total health } \\
\text { expendiabetes (100 } \\
\text { diare as a } \\
\text { million yuan) } \\
\text { proportion of total } \\
\text { expenditure (\%) }\end{array}$ & $\begin{array}{l}\text { Expenses attributable } \\
\text { to diabetes accounted } \\
\text { for the proportion of } \\
\text { patients' total } \\
\text { expenses (\%) }\end{array}$ \\
\hline Outpatient & 2.29 & 17994.92 & 11.18 & 3572.18 & 2012.28 & 19.85 \\
Hospitalized & 2.91 & 17325.81 & 15.71 & 4147.62 & 2722.32 & 23.94 \\
Total cost & 2.68 & 40974.64 & 14.09 & 9207.86 & 5772.09 & 22.47 \\
\hline
\end{tabular}

\section{Conclusion}

This study uses CHARLS data, uses the PSM method to study the impact of diabetes on residents' medical and health expenditures, and further analyzes the Chinese expenditure attributable to diabetes directly caused by diabetes. The results of the study show that diabetes has significantly increased residents' medical and health expenditures, and medical expenses attributed to diabetes account for more than half of all diabetes-related expenses. From the perspective of outpatient expenditure, the outpatient expenses of diabetic patients are significantly higher than that of non-diabetic patients. Among them, the cost of medicine accounts for a relatively large proportion, and the proportion of out-of-pocket health expenses for diabetic patients has not been significantly reduced. In terms of hospitalization expenditure, the difference between diabetic patients and non-patients is the largest.

Outpatient clinics are the main way for diabetic patients to receive medical treatment, and they are mainly based on the cost of medicines. We should focus on improving the outpatient clinics and medicine compensation for patients. At present, China has implemented a long-term prescription system for chronic diseases such as diabetes, prioritized the use of centralized procurement of drugs, and increased the proportion of outpatient reimbursement (over 50\% for urban and rural residents) to reduce the direct and indirect medical expenses of diabetic patients. If this policy truly benefits the masses, it is necessary to open up the last mile, let more patients know the policy, and simplify the application procedures. Hospitalization expenditure is based on the severity of the disease of the hospitalized patient, which may be accompanied by a larger number of other comorbidities. Therefore, we should start with delaying the development of the disease, strengthen early intervention and health education for patients with diabetes, so that patients can use as little or no inpatient services as possible, which can minimize the medical expenses of patients. In addition, whether it is outpatient or hospitalization, drug fees are the main source of patients' medical expenses. Therefore, in the next step of work, it is necessary to reduce drug costs as the main means, and further expand the implementation of the centralized drug purchase policy in order to reduce the 
burden on patients. At the same time, it can also improve the quality of medication.

\section{References}

[1] International Diabetes Federation. (2019). IDF Diabetes Atlas -9th edition. Available: https://www.diabetesatlas.org/upload/resources/material/2020 0302_133351_IDFATLAS9e-final-web.pdf. Accessed: Sep. 7, 2020 .

[2] International Diabetes Federation. IDF Diabetes Atlas -6th edition. (2013). Available: https://www.diabetesatlas.org/upload/resources/previous/files/ 6/IDF\%20Diabetes\%20Atlas\%206th\%20edition\%20-\%20chin ese.pdf. Accessed: Sep. 8, 2020.

[3] N Xu, K J Liu, X F Gu, et al. (2016). The Research on Total Medical Expenses of Patients with Diabetes. Chinese Health Economics, 35 (10): 65-68.

[4] X Y Ming, L Yang, Q Sun, et al. (2019). The Disease Economic Burden and Influence of Diabetes in Sichuan Province. Health Economics Research. 36 (01): 29-31+37.

[5] Y Leng, Y N Li, J Deng. (2019). Analysis of the Economic Burden of Diseases in Middle-aged and Elderly Patients with Diabetes in China. Health Economics Research. 36 (01): 29-31+37.

[6] X X Wang, D Hu, Y Zhu, et al. (2020). An Empirical Study on the Economic Burden of Diabetes in Jiangsu Province. Chinese Primary Health Care, 34 (02): 5-9.

[7] American Diabetes Association. (2013). Economic costs of diabetes in the U.S. in 2012. Diabetes Care. 36: 1033-1046.

[8] American Diabetes Association. (2017). Economic Costs of Diabetes in the U.S. in 2017. Diabetes Care, 2018: 917-928.
[9] H P Wang, Z Y Hou, Q Y Meng. (2013). A comparative study on medical expenditure for diabetes mellitus and non-diabetes mellitus in 9 provinces of China, between 2000 and 2009 . Chinese Journal of Epidemiology, 34 (9): 911-913.

[10] Rosenbaum, P. R. \& Rubin, D. B. (1983). The Central Role of the Propensity Score in Observational Studies for Causal Effects. Biometrika, 70 (1): 41-55.

[11] Josson B. (1998). The economic impact of diabetes. Diabetes Care, 21 suppl 3: C7-C10.

[12] M He, X J Tang, Q Long, et al. (2016). Influencing Factors of Diabetic Patients Applying for specific disease Health Insurance and its treatment cost. Journal of Zhejiang University (Medical Sciences), 045 (003): 323-329.

[13] Y Z Zhang, S P Yang. (2020). Does medical insurance promote the utilization of medical services for the rural elderly? Empirical analysis based on propensity score matching. Statistics and Management, 35 (05): 78-83.

[14] W Y Yang, W H Zhao, J Z Xiao, et al. (2017). Medical care and payment for diabetes in China: enormous threat and great opportunity. PLoS ONE7 (9).

[15] W H Zhao. (2012). The Study on Direct Economic Burden of Diabetes in China. Peking Union Medical College, 2012.

[16] Z W Zhang. (2007). The Study on the Burden of Diabetes in China. Fudan University, 2007.

[17] R Li, Bilik D, Brown MB, et al. (2013). Medical costs associated with type 2 diabetes complications and comorbidities. Am J Manag Care, 19 (5): 421-30.

[18] Marcellusi A, Viti R, Sciattella P, et al. Economic aspects in the management of diabetes in Italy. BMJ Open Diabetes Res Care. 